Gregory C. Allen MD FRCPC, Jan Charles Horrow MD, Henry Rosenberg MD

\section{Does forehead liquid crystal temperature accurately reflect "core" temperature?}

LCT au front peut être utile afin de mesurer la température et détecter une élévation rapide de la température corporelle quand d'autres moyens invasifs pour mesurer la température sont inappropriés ou non-disponibles.

rectal temperature, and axillary skin temperature to in distal oesophageal temperature during rapid warming on cardiopulmonary bypass. In 24 patients undergoing open heart surgery, temperatures were measured during the rapid warming phase on bypass (12-35 min). Scattergrams of temperature vs time for the four temperature sites each contained 150 data points. Polynomial regression analysis revealed that $L C T$, but not axillary or rectal temperatures, correlated with oesophageal temperature. We conclude that forehead LCT may be useful to monitor temperature trends and to detect rapid elevations in body temperature when more invasive temperature monitoring is inappropriate or unavailable.

La thermométrie à crystal liquide (LCT) est une alternative non-invasive pour surveiller la température corporelle. On a évalué durant la phase de réchauffement rapide lors d'une circulation extracorporelle, la capacité de la LCT mesurée au front, la température rectale, et la température cutanée axillaire, les comparant a la température asophagienne distale. Chez 24 patients subissant une chirurgie cardiaque, les températures furent mesurées lors du réchauffement rapide par la CEC (12-35 minutes). Les courbes de dispersion de la température versus le temps pour les quatre sites de mesure de la température contenaient chacune 150 points de mesure. L'analyse de régression polynomiale a révélé que la $L C T$, mais non la température axillaire ou rectale, montrait une corrélation avec la température asophagienne. On conclut que la mesure de la

\section{Key words}

SURGERY: cardiopulmonary bypass;

TEMPERATURE: monitoring.

From the Department of Anesthesiology, Hahnemann University, Broad \& Vine, Philadelphia, PA 19102-1192.

Address correspondence to: Dr. J.C. Horrow.

Presented at the 1 lth Annual Meeting of the Society of Cardiovascular Anesthesiologists, April 15-19, 1989, Seattle, WA. Supported in part by the Hahnemann Anesthesia Research Foundation and Mon-a-Therm Inc., St. Louis, MO.
For a variety of reasons, body temperature may change under anaesthesia. ' Some temperature changes are predictable, but other unexpected events, e.g., malignant hyperthermia (MH) or accidental hypothermia, may occur. For this reason, several authors have recommended that body temperature be monitored in all patients receiving anaesthesia. ${ }^{2-4}$ The clinician must decide whether or not to monitor body temperature, and if so, at what site, and with what device. This is particularly true in many elective surgical procedures, where temperature changes are not anticipated. In such cases, a device which accurately detects trends in temperature change may be all that is required.

Liquid crystal thermometry (LCT) is a non-invasive method of monitoring skin temperature. The claim that forehead LCT both rapidly and accurately follows trends evaluated the ability of LCT, rectal (RT), and axillary skin temperature (AT) to reflect distal oesophageal temperature (ET) during the rapid changes in core temperature that occur with warming on cardiopulmonary bypass (CPB).

\section{Methods}

With institutional approval, 24 patients undergoing coronary revascularization procedures gave informed consent and entered the study. None of the patients had diabetes or peripheral vascular disease. Premedication consisted of intramuscular morphine and scopolamine. Anaesthesia was induced and maintained with fentanyl (50-150 $\left.\mu \mathrm{g} \cdot \mathrm{kg}^{-1}\right)$ or sufentanil $\left(5-12 \mu \mathrm{g} \cdot \mathrm{kg}^{-1}\right)$, oxygen, and a' non-depolarizing muscle relaxant. No volatile anaesthetic agents were used.

An internally calibrated thermocouple (Mon-a-Therm 6500 , St. Louis, MO) with $0.1^{\circ} \mathrm{C}$ precision measured ET, AT, and RT. Temp-A-Strip (Sharn Inc., Tampa, FL) in core temperature changes ${ }^{5,6}$ has been disputed. ${ }^{7}$ We 
displayed LCT with $0.5^{\circ} \mathrm{F}$ precision and a range of 85 to $103^{\circ} \mathrm{F}$. An oesophageal stethoscope contained the ET thermocouple in its tip; it was placed in the distal third of the oesophagus, at the point where heart tones were loudest. ${ }^{8}$ Arm adduction insulated the AT probe following its placement in the mid-axilla. The rectal probe was inserted a minimum of $8 \mathrm{~cm}$, then taped in place. The LCT strip was placed in the centre of the patient's forehead.

Hypothermic CPB utilized crystalloid prime, a Bentley- 10 bubble oxygenator and a Sarns heater-cooler. Average pump flows on CPB were $2.2 \mathrm{~L} \cdot \mathrm{min}^{-1} \cdot \mathrm{m}^{-2}$. Patients were cooled to $25-28^{\circ} \mathrm{C}$. (ET) while on CPB. Warming continued until ET and RT exceeded $37^{\circ} \mathrm{C}$ and $35^{\circ} \mathrm{C}$, respectively. A Blanketrol warming blanket, set at $37-40^{\circ} \mathrm{C}$, was used during and after warming. When necessary, nitroglycerin or nitroprusside intravenously maintained mean arterial pressure below $70 \mathrm{mmHg}$.

From the onset of warming on $\mathrm{CPB}$, temperatures were recorded at times $0,5,10,12,14,16,18,20,25,30,35$, $40 \mathrm{~min}$, and every $10 \mathrm{~min}$ thereafter. The assistant recording data was unaware of the purpose of the study. For each site of temperature measurement, temperature vs time data points for all patients were plotted during the period of most rapid core warming (12-35 min). Results for LCT were converted to Celsius for analysis. Sequential polynomial regression analysis was performed, ${ }^{9,10}$ using the Statview II statistical program (Abacus Concepts, Inc., Berkeley, CA 94704, USA) on an Apple ${ }^{\circledR}$ Macintosh computer. Data of continuous variables are reported as mean \pm standard deviation. $P<0.05$ determined statistical significance.

\section{Results}

The 24 patients, aged $60 \pm 10 \mathrm{yr}$, weighed $82 \pm 16 \mathrm{~kg}$ (body mass index $27 \pm 5 \mathrm{~kg} \cdot \mathrm{m}^{-2}$ ). At the start of warming on $\mathrm{CPB}$, ET was $26.3 \pm 1.5^{\circ} \mathrm{C}$, RT was $27.4 \pm$ $1.9^{\circ} \mathrm{C}$, AT was $28.1 \pm 2.6^{\circ} \mathrm{C}$, and LCT was off scale (< $85^{\circ} \mathrm{F}$ ). Warming lasted $37 \pm 10 \mathrm{~min}$. Because LCT was off scale at $12 \mathrm{~min}$ in 42 observations, analysis included only 150 of a possible 192 sets of data. A gradient between core temperature (ET) and each of the other temperatures existed throughout warming, with the ETAT difference at $5.8 \pm 2.6^{\circ} \mathrm{C}$, the ET-RT difference at $3.8 \pm 2.3^{\circ} \mathrm{C}$, and the ET-LCT difference at $3.3 \pm 1.8^{\circ} \mathrm{C}$. Each difference was distinct from zero by paired $t$ test $(n$ $=150, P<0.0001)$. The ET-AT difference was greater than either the ET-RT difference or the ET-LCT difference $(P<0.05$ by analysis of variance and Scheffés F-test).

Figure 1 displays the scattergrams depicting temperature vs time for each site of measurement. While simple linear regression analysis could be performed on this data, the scattergrams displayed a plateau effect which obli-

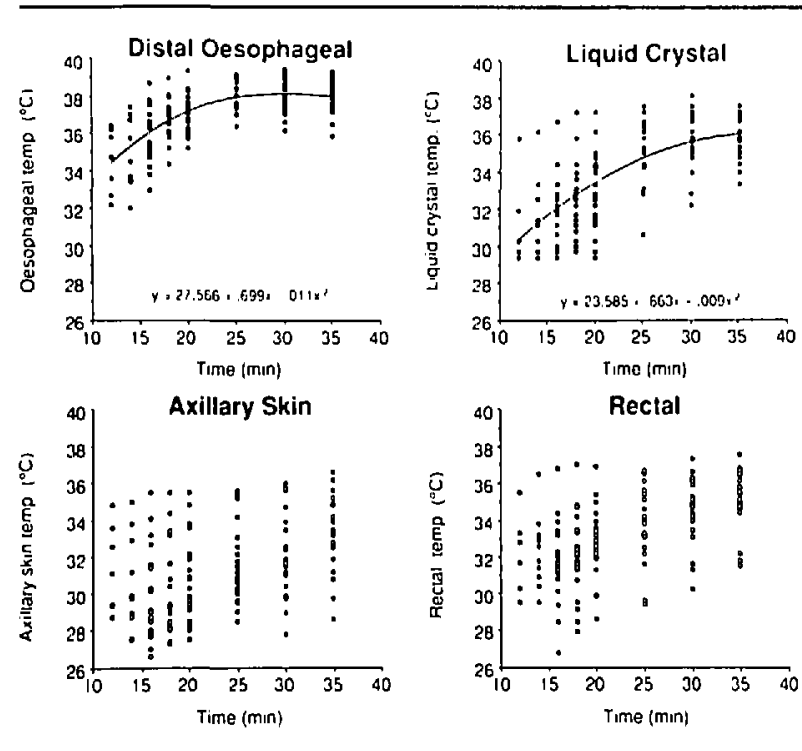

FIGURE 1 Temperature vs time scattergrams for each temperature measured. Regression lines and equations are shown only for ET and LCT. See results section for details.

gates one to test the suitability of a curvilinear relationship. ${ }^{10}$ Parsimony dictates that the lowest possible order polynomial be sought. The partial $F$ statistic from the regression analysis of variance determines significance of the highest term's contribution to the regression expression. Polynomial regression of order $3\left(\mathrm{X}^{3}\right)$ and above did not account for a significantly increased variance (partial $F$ all $\leq 2.5, P=N S$ ). For ET and LCT, quadratic $\left(\mathrm{X}^{2}\right)$ terms did account for significantly more variance over the simple linear model (partial $F=28.3$ for ET and 7.16 for LCT, each $P<0.01$ ). ET and LCT vs time regression equations featured correlation coefficients of 0.71 and 0.69 respectively. Quadratic coefficients for the AT and RT vs time regressions were not significantly different from zero.

The Table lists beta coefficients for the regression analysis of each temperature with time. The $X^{2}$ coefficient represents curvature of the regression line, while it and the $X$ coefficient determine a curve's steepness. The $b$ values represent $Y$-intercepts. Beta coefficients for ET and LCT were all significantly different from zero. For $A T$ and $R T$, quadratic regression produced non-significant results,

TABLE Results of quadratic regression analysis

\begin{tabular}{lrrrr}
\hline & \multicolumn{1}{l}{$X^{2} \pm S E M$} & $S \pm S E M$ & $b$ & $r$ \\
\hline ET & $-0.011 \pm 0.002^{*}$ & $0.699 \pm 0.105^{*}$ & 27.6 & 0.71 \\
LCT & $-0.009 \pm 0.003^{*}$ & $0.663 \pm 0.163^{*}$ & 23.6 & 0.69 \\
RT & $0.002 \pm 0.004$ & $0.073 \pm 0.180$ & 30.4 & 0.54 \\
AT & $0.007 \pm 0.004$ & $-0.213 \pm 0.204$ & 31.9 & 0.43 \\
\hline
\end{tabular}

${ }^{*}$ Coefficients significantly different from zero $(P<0.001)$. 


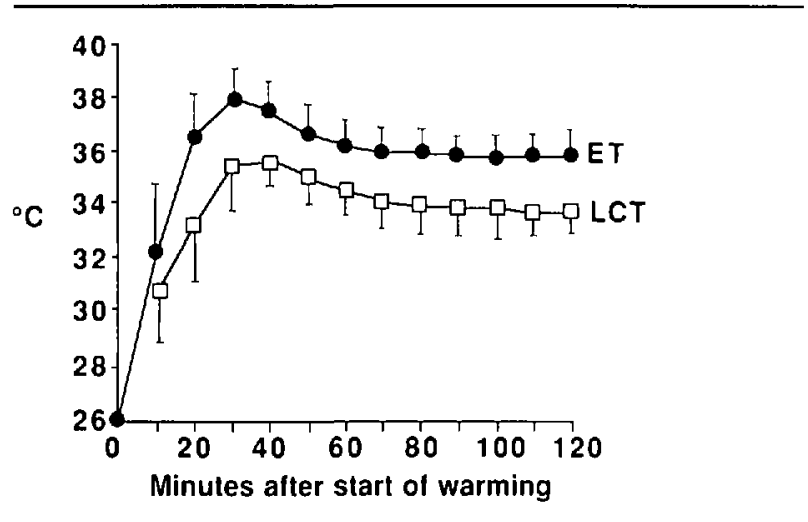

FIGURE 2 Mean temperature ( $\pm \mathrm{SD}$ ) vs time (min) for LCT (open squares) and ET (closed circles) for $120 \mathrm{~min}$ after the onset of warming on $\mathrm{CPB}$.

i.e., no relationship. While simple linear regression of the AT and RT vs time data did produce $\mathrm{X}$ coefficients different from zero, the correlation coefficients were poor (0.43 and 0.54 respectively). There was no significant difference between ET and LCT in either the $X^{2}$ (curvature) or $\mathrm{X}$ coefficients of the regression equations (unpaired $t$ test). Therefore the curves were parallel. Figure 2 illustrates this parallelism by displaying the mean values ( $n=24$ patients) of ET and LCT vs time. LCT trended the increases in ET, with a mean gradient of $3.3^{\circ} \mathrm{C}$.

\section{Discussion}

In this study, we observed that forehead LCT paralleled ET during rapid warming on CPB; RT and AT did not. The thermal gradients between core and more peripheral sites produced by warming on CPB resulted in lower values for AT, RT, and LCT compared with ET. The similar $X$ and $X^{2}$ coefficients of the LCT and ET curves (Table, Figure 2) indicate that LCT closely followed ET.

Warming after CPB has previously been used for studying rapid temperature changes in anaesthetised patients. Burgess et al. compared forehead LCT with ET, RT, and AT during the course of hypothermic CPB in 20 patients. ${ }^{6}$ In that study, LCT, AT, and RT all closely paralleled ET. They concluded that LCT performed well as a trend indicator, and could be used when continuous invasive temperature monitoring was not necessary. In the present study, AT and RT did not parallel ET. This may have been because our patients were cooler at the onset of warming than those of Burgess et al. The larger thermal gradients delayed increases in RT and AT. LCT may have also paralleled ET more closely than RT or AT because forehead skin blood flow increased during warming on CPB. Sweating is often observed during warming, " and has been attributed to light anaesthesia. However, sweating probably occurs as part of the normal thermoregulato- ry mechanism ${ }^{11,12}$ by which the hypothalamus attempts to decrease brain temperature when blood infused from the pump exceeds $37^{\circ} \mathrm{C}$ during warming.

Passive systemic hyperthermia, used to treat certain malignancies, ${ }^{13}$ has also been used as an experimental model of rapid temperature elevation to assess LCT. Lees et $a l .^{5}$ found that forehead LCT paralleled ET in patients warmed to oesophageal temperatures of $41.8^{\circ} \mathrm{C}$, whereas RT did not. They concluded that LCT may be an adequate screening device to detect intraoperative hyperthermia.

It has been questioned whether LCT can accurately detect changes in core temperature intraoperatively. ${ }^{14.15}$ These studies showed a poor correlation between forehead LCT and tympanic membrane temperature (TMT) during general anaesthesia, where TMT decreased $1-2^{\circ}$ C. Also, during recovery from anaesthesia, LCT did not correlate well with TMT. ${ }^{7}$ It is debatable whether TMT should be used to represent core temperature. During passive hyperthermia, TMT reflects neither intracardiac blood temperature nor ET. ${ }^{16}$ Protective heat control mechanisms lower brain temperature to prevent central nervous system damage, ${ }^{12,16}$ thus attenuating increases in TMT during hyperthermia.

The current analysis employed regression of each temperature against time rather than correlation coefficients of LCT with other temperatures, as calculated in previous work. $7,14,15$ The latter technique addresses the ability of LCT to substitute for another temperature, whereas the former analysis technique retains the temporal variable necessary to evaluate for similar changes with time, i.e., trending. The different questions posed by this study compared with others ${ }^{7,14,15}$ and the appropriately different statistical analyses may also account for the different results. For comparison, correlation coefficients of data in the current study are 0.67 (ET-LCT), 0.39 (ET-RT), and 0.25 (ET-AT).

Casey et al. have shown that in anaesthetised paediatric patients, forehead LCT is as accurate as AT in measuring body temperature. ${ }^{17}$ Both AT and LCT paralleled ET closely. The authors concluded that LCT may be a useful alternative temperature monitor in children. Differences in skin blood flow between children and adults may explain why their results conflict with those of adults. ${ }^{14,15}$ Whether LCT can accurately detect temperature elevation during an acute $\mathrm{MH}$ episode has been disputed. Lacoumenta and $\mathrm{Hall}^{14}$ have stated that the high levels of catecholamines present during an $\mathrm{MH}$ episode result in peripheral vasoconstriction, rendering skin temperature measurements worthless. However, Williams et al. ${ }^{19}$ have shown that heat loss due to radiation actually increases during the first 20 min of an MH episode, then declines as catecholamine levels rise and peripheral vasoconstriction develops. ${ }^{19}$ Therefore, one might expect 
an increase in skin temperature early in an $\mathrm{MH}$ crisis as the body tries to dissipate heat. This might be detectable using LCT.

We conclude that forehead LCT reflects core temperature, as represented by ET, better than RT or AT do during warming on cardiopulmonary bypass. While LCT successfully parallels rapid changes in core temperature, it cannot replace invasive core temperature monitors.

\section{Acknowledgement}

The authors thank L. Feinerman M.D., J. Jaffe, and A. Harmon for assistance in the conduct of this investigation.

\section{References}

1. Hall GM. Body temperature and anaesthesia. $\mathrm{Br} \mathrm{J}$ Anaesth 1978; 50: 39-44.

2. Cork RC. Temperature monitoring. In: Blitı CD, (Ed.). Monitoring in Anesthesia and Critical Care Medicine.

New York: Churchill-Livingstone, 1985: 441-57.

3. Britt BA. Temperature regulation. In: Gregory GA, (Ed.). Pediatric Anesthesia. New York: Churchill-Livingstone, 1983: 298-9.

4. Rosenberg $H$, Seitman D. Pharmacogenetics. In: Barash PG, Cullen BF, Stoelting RK, (Eds.) Clinical Anesthesia. Philadelphia: Lippincott, 1989: 459-83.

5. Lees DE, Schuette W, Bull JM, Whang-Peng J, Atkinson $E R$, MacNamara TE. An evaluation of liquid-crystal thermometry as a screening device for intraoperative hyperthermia. Anesth Analg 1978; 57: 669-74.

6. Burgess GE, Cooper JR, Marino RJ, Peuler MJ. Continuous monitoring of skin temperature using a liquidcrystal thermometer during anesthesia. South Med J 1978; 71 : 516-8.

7. Vaughn MS, Cork $R C$, Vaughn $R W$. Inaccuracy of liquid crystal thermometry to identify core temperature trends in post-operative adults. Anesth Analg 1982; 61: 284-7.

8. Kaufman $R D$. Relationship between esophageal temperature gradient and heart and lung sounds heard by esophageal stethoscope. Anesth Analg 1987; 66: 1046-8.

9. Snedecor GW, Cochran WG. Statistical Methods, 7th ed. Ames, Iowa: Iowa State University Press, 1980: 398-401.

10. Cohen J, Cohen P. Applied Multiple Regression/ Correlation Analysis for the Behavioral Sciences. New York: Wiley, 1975: 214-9.

11. Tinker $J H$, Roberts SL. Management of cardiopolmonary bypass. In: Kaplan JA (Ed.). Cardiac Anesthesia, 2nd ed. Orlando: Grune \& Stratton, 1987: 895-926.

12. Brinnel $H$, Nagasaka T, Cabanac $M$. Enhanced brain protection during passive hyperthermia in humans. Eur J Appl Physiol 1987; 56: 540-5.
13. Bull JM. A review of systemic hyperthermia. Front Radiat Ther Oncol 1984; 18: 171-6.

14. Lacoumenta S, Hall GM. Liquid crystal thermometry during anaesthesia. Anaesthesia 1984; 39: 54-6.

15. Cork RC, Vaughn RW, Humphrey LS. Precision and accuracy of intraoperative temperature monitoring. Anesth Analg 1983; 62: 211-4.

16. Shiraki K, Konda N, Sagawa S. Esophageal and tympanic temperature responses to core blood temperature changes during hyperthermia. J Appl Physiol 1986; 61: 98- 102 .

17. Casey WF, Broadman LM, Rice $W$, Dailey M. Comparison of liquid crystal skin temperature probe and axillary thermistor probe in measuring core temperature trends during anaesthesia in pediatric patients [abstract] Can J Anaesth 1989; 36: S62.

18. Williams $C H$, Houchins $C$, Shanklin MD. Pigs susceptible to energy metabolism in the fulminant hyperthermia stress syndrome. Br Med J 1975; 3: 411-3.

19. Gronert GA, Theye RA. Halothane-induced porcine malignant hyperthermia: metabolic and hemodynamic changes. Anesthesiology 1976; 44: 36-43. 